\title{
DOES SIZE MATTER: SCALING A COMPOSTING EXPERIMENT
}

\author{
Mait Kriipsalu ${ }^{I, 2}$ \\ Diauddin Nammari ${ }^{l}$ \\ ${ }^{\prime}$ University of Kalmar, Sweden \\ ${ }^{2}$ Estonian University of Life Sciences, Estonia
}

\begin{abstract}
Composting has been considered one of the simplest and most cost-effective methods for biotreatment of oily soil, sludge and sediments. By nature, composting is a large-scale process, where certain mass is needed to retain heat and moisture. In order to optimize composting, especially with oily wastes, various experiments may be necessary. To represent the composting process in small scale, in particular the magnitude and duration of temperature profiles, adequate scaling is required. Small-scale composting experiments were conducted in order to be able to analyze the scaling-up effects of laboratory and pilot-scale experiments into full-scale composting. Four naturally ventilated box reactors of different volumes: $2 \mathrm{~L}$, 20L, 200L, and 1000L were used. The compost mixture consisted of oily sediments, sawdust, and peat. The temperature of all compost mixtures was recorded daily at the centre and surface of each compost box, during a period of ten months. It was found, that the reactors with a volume $\leq 200 \mathrm{~L}$ and a surface area to volume ratio $(\mathrm{SA}: \mathrm{V}) \geq 10: 1$, showed no difference between surface and centre temperature. The heat generated was lost to the surroundings at a higher rate than could be sustained by the biomass. While the $1000 \mathrm{~L}$ experiment with a SA:V ratio in the range of $6.0: 1$ produced pronounced self heating. The results were in accordance to the SA:V ratios and their relationship to heat generation and dissipation as shown in scientific literature. The results obtained, show that laboratory experiments with self-heating reactors of $\mathrm{SA}: \mathrm{V}$ ratio $\geq 10: 1$ containing oily-sludge should not be used to simulate full scale, since the results are impossible to verify. In order to carry out reliable experiments simulating full scale composting processes in inexpensive self-heating reactors, it is suggested not to proceed with laboratory scale, but conduct properly insulated pilot-scale experiments with $\mathrm{SA}: \mathrm{V} \leq 6.0: 1$.
\end{abstract}

\section{KEYWORDS}

Surface area to volume ratio; Self-heating; Oily sludge compost

\section{INTRODUCTION}

Composting has been considered one of the simplest and most cost-effective methods of biotreatment $[1,2]$, that can be adapted to treat a wide variety of organic wastes, including oily sludge and sediments. In composting the degrading capacity of micro-organisms is enhanced by correcting some of the environmental factors that limit bioactivity. Most important parameters for microorganisms are availability of organic material, temperature, oxygen supply, moisture content, and $\mathrm{pH}$. As different from municipal waste composting, 
lower temperatures and longer degradation period are characteristic to composting of oily soil. The objective for composting of oily waste is to mineralize the hazardous chemical into inorganic compounds such as carbon dioxide, other gases or inorganic substances, water, and micro-organism biomass $[3,4,5,6]$. By nature, composting is a large-scale process, where certain mass is needed to retain heat in cold and windy environment, or retain moisture during summer.

Full-scale process optimisation requires experimentation, however, it may be expensive, difficult to control, and poorly replicable [7]. Full-scale situation is frequently less than ideal since operational practices may vary widely, both from site to site and within a site [7]. When hazardous compounds are involved in full-scale experimentation with oily compost, permits and licenses have to be acquired. If the process fails, large amounts of compost may have to be disposed of to hazardous waste landfills, or incinerated. In order to optimize various composting parameters, it may be necessary to experiment indoors, in laboratory or pilot scale. In well-controlled laboratory conditions, research appears to discover the phenomena, which has to be controlled and generalized in full-scale [8]. Experimental systems are expected to simulate the operational parameters for full-scale composting.

Experiments at less than full scale are better controlled, and require relatively small quantities of materials and other resources. However, these benefits compromise by a certain loss of the 'reality' which is inherent at full scale, in particular the magnitude and duration of temperature profiles [9]. Thermodynamic factors affecting the generation and transfer of heat in the composting system are important [8] because of their effect on biological activity, moisture and water vapour transport, natural ventilation, volatilisation, viscosity of hydrocarbons (if present), oxygen status and temperature distribution patterns.

In order to adequately represent the full-scale composting process at laboratory and pilot level, appropriate reactor type, technology, and compost mixture must be selected. Laboratory and pilot scale experiments can be performed in various types of reactors [9]:

- In fixed temperature reactors the desired composting temperature is imposed and maintained by means of external heating or cooling;

- Self heating reactors rely only on microbial heat and have no temperature control besides optional external insulation;

- In reactors with controlled temperature, heat from microbial production is used to reach and maintain process temperatures and heat losses are controlled by supplying heat to the outer surface of the vessel. Pre-determined temperature difference or pre-determined heat flux across the composting material is maintained.

One of the main parameters in selecting small-scale reactor is surface area to volume ratio $(\mathrm{SA}: \mathrm{V})$. The larger the outer perimeter of the test-reactor comparing its volume is, the more heat losses may be expected. Insulating of reactors may give a positive effect, however, as demonstrated by Mason and Milke [9], theoretical required thickness of polyurethane insulation increases exponentially with $\mathrm{SA}: \mathrm{V}$ increase.

Other process parameters are also important to select. Oxygen is used as an electron acceptor during aerobic degradation of waste. Adequate aeration must be provided via forced (fixed or alternated) or natural aeration. Fixed forced aeration rates have been most frequently reported in laboratory-scale research. Oxygen release compounds can be used for degradation of contaminants in soil [10], but is not common in composting. 
A series of indoor composting experiments were conducted in a laboratory of department of Water Management in Estonian Agricultural University (EAU). It was targeted to analyze the scaling-up effects of laboratory and pilot-scale experiments into full-scale composting. The objective was to determine the minimum reasonable size of a laboratory or pilot scale experiment that can be conducted indoors when attempting to compost oily soil, sludge and sediments.

\section{METHODS}

Compost mixture was prepared by the mixing of oily sediments from a full-scale remediation works at Laguja Landfill with well decomposed peat, small amount of shredded bark, and small amount of fine sawdust. The remediation work has been described earlier [11]. The material was thoroughly mixed in a standard concrete mixer and placed in plywood reactors of different volume (Table 1).

\section{Table 1. Experiment design parameters}

\begin{tabular}{lllcc}
\hline Reactor & Volume $\mathrm{m}^{3}$ & Dimensions $\mathrm{m}$ & Surface area $\mathrm{m}^{2}$ & $\mathrm{SA} / \mathrm{V}$ ratio $\mathrm{m}^{2} / \mathrm{m}^{3}$ \\
\hline 1 & 1 & $1.00 \times 1.00 \times 1.00$ & 6.000 & 6.00 \\
2 & 0.2 & $0.58 \times 0.58 \times 0.58$ & 2.018 & 10.09 \\
3 & 0.02 & $0.27 \times 0.27 \times 0.27$ & 0.437 & 21.85 \\
4 & 0.002 & $0.12 \times 0.12 \times 0.12$ & 0.086 & 43.00 \\
\hline
\end{tabular}

Naturally ventilated and not insulated self-heating reactors were used. The bottoms of the boxes were made of plastic net, and placed on pallets to avoid ground contact. The experiment was performed at room temperature. Occasionally, moisture was added during the experiment, but the compost was further not mixed or disturbed.

The temperature of all compost mixtures was recorded daily using Amarell GmbH \& Co. KG Multi E 905000 series portable digital thermometers with 125, 300 and $500 \mathrm{~mm}$ probe length. The range of the thermometers was -50 to $+200^{\circ} \mathrm{C}$, resolution $0.1^{\circ} \mathrm{C}$, and accuracy $<1^{\circ} \mathrm{C}$. Thermometer was permanently inserted into the centre $\left(\mathrm{T}_{\mathrm{av}}\right)$ of each compost box, and placed on the surface $\left(\mathrm{T}_{\text {ext }}\right)$ (Figure 1$)$. The ambient temperature $\left(\mathrm{T}_{\text {air }}\right)$ was also measured. Readings were collected during 250 days.

Analysis of the heat loses through the walls were presented, using a steady state heat transfer formula (see Equation 1).

$\frac{\partial^{2} T}{\partial x^{2}}+\frac{\partial^{2} T}{\partial y^{2}}+\frac{\partial^{2} T}{\partial z^{2}}+\frac{g}{k}=0$

where $T[K]$ it the temperature, $g\left[W / m^{3}\right]$ is the heat generation, and $k\left[W / m{ }^{o} C\right]$ the thermal conductivity, and $x, y, z$ are the coordinate system. The thermal conductivity $(k)$ of the compost mixture (peat, wood chips and sawdust) was taken as $0.1 \mathrm{~W} / \mathrm{m}{ }^{\circ} \mathrm{C}$. The effect of a wall thickness of plywood boxes $(3 \mathrm{~mm})$ was considered irrelevant. 


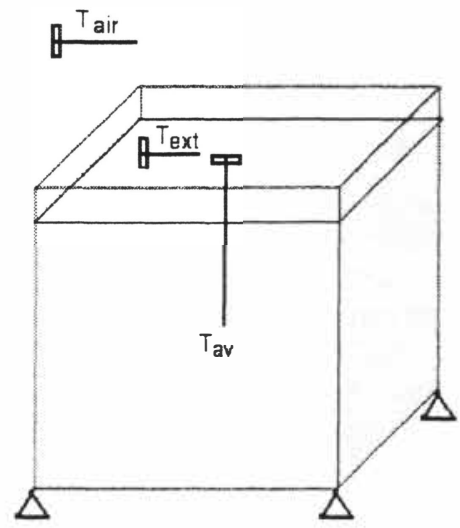

Figure 1. Schematic of temperature measurements.

Mathematical numerical methods were used to calculate the heat generation according to Equation 2.

$g=k\left(\frac{T_{e x t}-2 T_{a v}+T_{e x t}}{\Delta x^{2}}+\frac{T_{e x t}-2 T_{a v}+T_{e x t}}{\Delta y^{2}}+\frac{T_{e x t}-2 T_{a v}+T_{e x t}}{\Delta z^{2}}\right)$

The content of petroleum hydrocarbons, measured as non-polar fraction was determined in the dry solids (DS) by infrared spectrometry in the laboratory of Tartu Environmental Research Ltd (Tartu, Estonia), according to the Finnish and Swedish standard methods (SFS 3010 and SS 028145 respectively).

\section{RESULTS AND DISCUSSION}

\subsection{Heat generation and transfer}

The experiment was set up in December with stable room temperatures around $15^{\circ} \mathrm{C}$. Minor temperature fluctuations can be explained with automatic setting of room temperature, according to outside air. Generation of heat was only observed in Reactor 1 (Figure 2, a), where the temperature in centre of the box was about $10^{\circ} \mathrm{C}$ higher. The Reactor 2 indicated slightly higher temperature than in air (Figure 2,b), however the temperature increase was not very significant. In Reactor 1 , the internal temperature rapidly increased, until plateau of about $25^{\circ} \mathrm{C}$ was reached. Elevated temperatures were maintained for 145 days, when central heating was switched off due to approaching spring (Figure 2, T), and the indoor air temperature equalised to outdoor one. Decrease in air temperature caused the decrease of temperature in all composts. The indoor temperature increased further, but compost heat generation did not recover, and compost followed the fluctuations of indoor air. In Reactors 3 and 4 (Figure 2, $c$ and $d$ ), the temperature in centre of the reactor was close to the room temperatures. Surface temperature and air temperature were relatively similar in all treatments. 


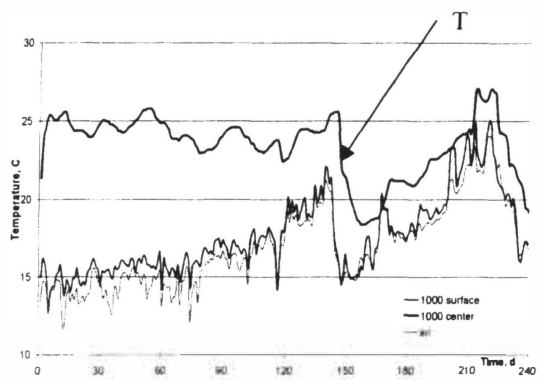

a) $1000 \mathrm{~L}$

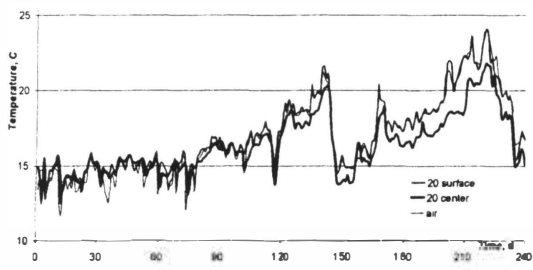

c) $20 \mathrm{~L}$

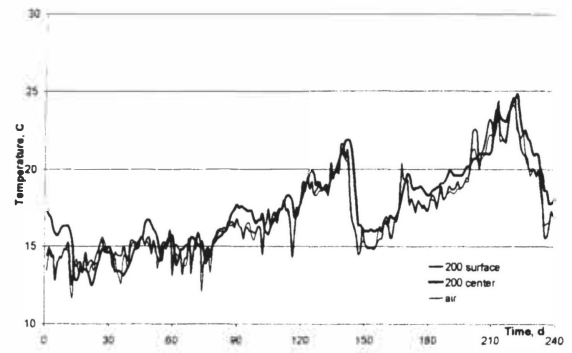

b) $200 \mathrm{~L}$

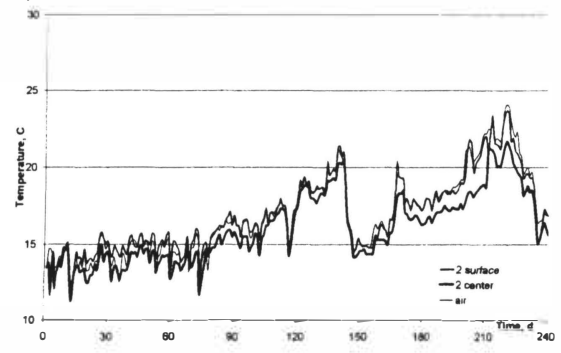

d) $2 \mathrm{~L}$

Figure 2. Temperatures as measured in the centre of the box, surface of the box and ambient.

\subsection{Surface area to volume ratio}

The heat generation was calculated according to Equation 2. It was assumed that relationship between SA/V and heat generation was exponential (Figure 3). Analysis of the heat generation was carried out only on day 5 and day 60 and the impact of the surface to volume ratio was analysed the results of which are shown in Figure 3. It is important to note that the relationship is assumed to be exponential up to $1000 \mathrm{~L}$, however, this is a simplification of reality, since at volumes below $1000 \mathrm{~L}$ can have biological activity that is self sustaining.

\subsection{Air flow and moisture content}

During the experiment, passive aeration through top and bottom of the reactor was used. Oxygen content in the reactors was not measured, since the compost remained coarse. Losses in moisture content indicated that movement of gases took place in compost. Water was added to the compost according to visual inspection during 8 events. Totally, 90L was added to Reactor 1; 23.5L to Reactor 2; 3.2L to Reactor 3; and $0.355 \mathrm{~L}$ to Reactor 4. Apparently, moistening was not sufficient, since moisture content lower than $45 \%$ was occasionally recorded. Reactors 3 and 4 failed to sustain moisture, which probably affected hydrocarbon degradation. 


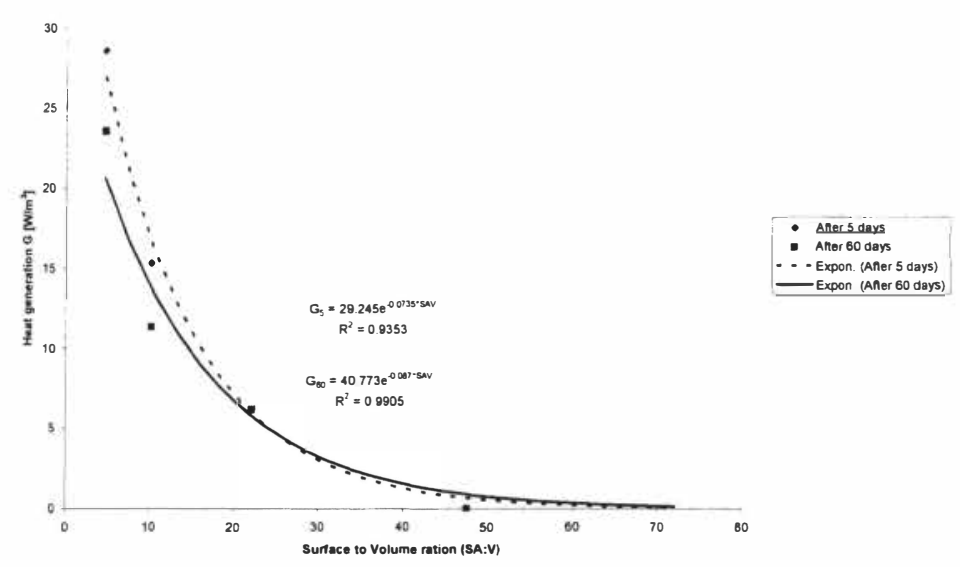

Figure 3. Exponential relationship between $S A: V$ and heat generation

Compost has to be kept aerobic. Fixed or alternate forced aeration, airflow effects, channelling and mixing may affect simulation performance. Forced aeration with fixed aeration rates have been most frequently reported in laboratory-scale research, whereas only a small number of published laboratory- and pilot-scale studies involve aeration by natural ventilation $[12,13]$. Reported ventilative heat losses from full-scale composting systems have ranged from $70 \%$ to $95 \%$ of the total flux, whilst losses from laboratory reactors were in the range $36 \%$ to $67 \%$ [14]. In case of forced aeration, automatic moistening system is recommended. Moistening of air, as well as drip irrigation may be used in simulation experiments.

\subsection{Insulation and external heat}

Insulation of reactors reduces heat losses. In laboratory experiments, glass or mineral wool, polystyrene, and polyurethane have been used as insulation material; in pilot experiments also bulk woodchips, straw, or other inexpensive materials. Thickness of insulation bases on theoretical calculations. According to Mason and Milke [9], the heat losses of 1000L, 200L, $20 \mathrm{~L}$, and $2 \mathrm{~L}$ experimental reactors would have been compensated by adding $46 \mathrm{~mm}, 85 \mathrm{~mm}$, $490 \mathrm{~mm}$, and $11.5 \mathrm{~m}$ of polyurethane insulation respectively (Figure 4). At pilot scale, even moderately insulated self-heating reactors are able to reproduce wall losses similar to those reported for full-scale systems. Heat losses in laboratory-scale reactors must be compensated by other means, by external heating, or by adding easily degradable energy amendments. Poultry manure will typically produce the most heat of the commonly available manures, followed by swine, sheep and cattle manure. Fresh manure has higher concentration of readily degradable organics, and will therefore produce more heat than old manure [4].

In controlled temperature difference and controlled heat flux laboratory reactors, spatial temperature differentials similar to those in full-scale systems, can be simulated [9]. 


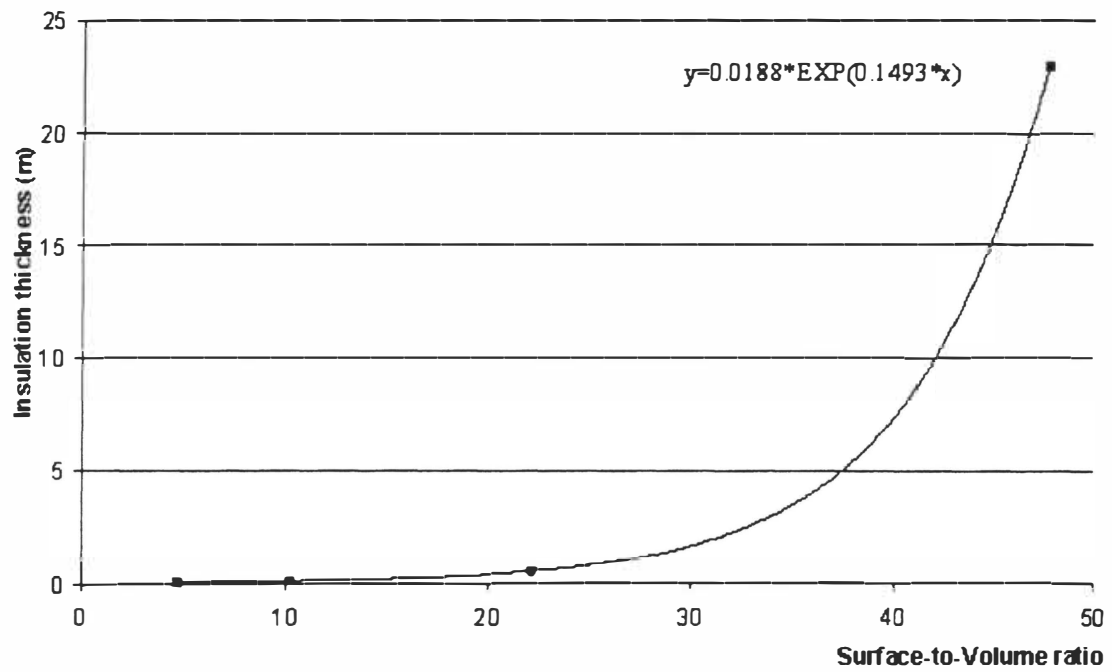

Figure 4. Thickness of polyurethane insulation, $m$. The points show the experimental $S A: V$ ratio and their theoretical insulation requirements

\subsection{Degradation of hydrocarbons}

After 250 days, the oil content had been reduced up to $48 \%$ in Reactor I (1000L), $33 \%$ in reactor II $(200 \mathrm{~L})$, but remained stable in Reactors 3 and 4 . This indicates that unfavourable conditions for hydrocarbon degradation dominated in $20 \mathrm{~L}$ and $2 \mathrm{~L}$ reactors. Fluctuations in temperature recorded in these reactors may have occurred because of degradation of easily degradable organic amendments.

\section{CONCLUSIONS}

Low-tech windrow composting of oily wastes is often done with limited monitoring and maintenance. The success depends on operational parameters and initial composition of compost, what in many cases bases on previous professional knowledge. Before attempting composting any 'difficults' waste, it may be necessary to conduct small-scale tests in a laboratory. Simulation of actual composting environment would help to optimize the processes. Various reactor types exist, where the self-heating reactor is simplest and cheapest.

Surface cooling by conduction is important in a small-scale composting. The minimum reasonable size for indoors composting experiment depends on surface area to volume ratio $(\mathrm{SA}: \mathrm{V})$. If the $\mathrm{SA} / \mathrm{V}$ ratio is large, more heat will be lost. Reactors can be classified by size as laboratory and pilot-scale. Surface area to volume ratios, a significant factor in terms of heat loss through vessel walls, were estimated at $5.0-88.0 \mathrm{~ms} \mathrm{~m}^{2}$ for experimental composting reactors and $0.4-3.8 \mathrm{~m}^{2} \mathrm{~m}^{-3}$ for full-scale systems. We found, that $2 \mathrm{~L} ; 20 \mathrm{~L}$; and $200 \mathrm{~L}$ reactors were behaving as laboratory-scale; and $1000 \mathrm{~L}$ as pilot-scale. Self-heating reactors at pilot scale have SA:V ratios closer to those in full-scale systems and may, with appropriate insulation, be able to provide a suitable thermodynamic environment [9]. We conclude that in our experiments, in volumes exceeding $200 \mathrm{~L}$, the microbes dominated in heat balance and 
losses of heat were of secondary importance. Self-heating laboratory-scale reactors, although inexpensive and uncomplicated, suffer from disproportionately large losses through the walls. It is suggested not to proceed with laboratory scale ( $2 \mathrm{~L}$ and $20 \mathrm{~L}$ ), but conduct properly insulated pilot-scale experiments with $\mathrm{SA}: \mathrm{V} \leq 6.0: 1$. Reactors with size between $200 \mathrm{~L}$ and $1000 \mathrm{~L}$ are recommended, whereas $1000 \mathrm{~L}$ is the largest reasonable size for indoor composting, since larger volumes are physically difficult to handle.

\section{ACKNOWLEDGEMENTS}

The financial support from the Royal Swedish Academy of Agriculture and Forestry (KSLA, Sweden), is acknowledged; as advice of Prof. William Hogland from the University of Kalmar, Sweden; and Mr Tõnu Salu from Estonian Agricultural University for experiment maintenance.

\section{REFERENCES}

[1] von Fahnestock, F. M., Wickramanayake, G. B., Kratzke, R.J., Major, W.R., 1998. Biopile design, operation, and maintenance handbook for treating hydrocarboncontaminated soils. Battelle Memorial Institute, Columbus Ohio. 163 p

[2] Eweis, J.B., Ergas, S.J., Chang, D.P.Y., Schroeder, E.D., 1998. Bioremediation Principles. McGraw-Hill International, New York, USA. 296 p.

[3] Norris, R.D. (Ed), 1994. In-situ bioremediation of soils and groundwater contaminated with petroleum hydrocarbons. In: Handbook of Bioremediation. Robert S. Kerr Environmental Research Laboratory. Lewis Publishers, USA. 257 p

[4] Peramaki, M.P.P.E., Blomker, K.R., 1997. Practical design considerations for composting contaminated soil. In: Leeson, A. A. \& Bruce C. (eds): Proceedings of the Fourth International In Situ and On-Site Bioremediation Symposium, New Orleans, April 28-May 1, Battelle press, USA.

[5] Cole, G.M., 1994. Assessment and Remediation of Petroleum Contaminated Sites, Lewis Publishers, Inc. CRC Press, Boca Raton, FL.

[6] Jorgensen, K.S., Puustinen, J., Suortti, A.-M., 2000. Bioremediation of petroleum hydrocarbon-contaminated soil by composting in biopiles. Environmental Pollution $107,245-254$.

[7] Hogan, J.A., Miller, F.C., Finstein, M.S., 1989. Physical modeling of the composting ecosystem. Applied and Environmental Microbiology 55 (5), 1082-1892.

[8] Graziano, A. M., Raulin, M. L., 2004. Research methods: a process of inquiry. Allyn and Bacon, Boston.

[9] Mason, I.sG., Milke, M. W., 2005. Physical modelling of the composting environment: A review. Part 1: Reactor systems. Waste Management 481-500.

[10]Koenigsberg S., Sandefur, C., 2001. The Efficacy of Oxygen Release Compound: A Six Year Review. A Sixth Annual In-Situ and On-Site Bioremediation Conference, San Diego, CA, June 3-7, 2001, Battelle Press, Columbus, OH.

[11] Kriipsalu, M., Marques, M., Hogland, W., 2005. Remediation of an oily leachate pond in Estonia. Waste management and Research 23, 1-9 (in press)

[12] Barrington, S., Choiniere, D., Trigui, M., Knight, W., 2003. Compost convective airflow under passive aeration. Bioresource Technology 86 (3), 259-266.

[13] Veeken, A., de Wilde, V., Hamelers, B., 2002. Passively aerated composting of strawrich pig manure: effect of compost bed porosity. Compost Science \& Utilisation 10 (2), 114-188. 
Kalmar ECO-TECH '05 and

The Second Baltic Symposium on Environmental Chemistry

KALMAR, SWEDEN, November 28-30, 2005

[14] Mason, I. G., Milke, M. W., 2005. Physical modelling of the composting environment: A review. Part 2: Simulation performance. Waste Management 501-509. 